\title{
Genomic insight into the scale specialization of the biological control agent Novius pumilus (Weise, 1892)
}

\author{
Xue-Fei Tang ${ }^{1 \dagger}$, Yu-Hao Huang ${ }^{1 \dagger}$, Hao-Sen Li ${ }^{1}$, Pei-Tao Chen ${ }^{1}$, Huan-Ying Yang ${ }^{1}$, Yuan-Sen Liang ${ }^{1}$, Xue-Yong Du',
} Zhen-Hua Liu' ${ }^{1}$, En-Feng Li ${ }^{2}$, Yu-Chen Yang ${ }^{1}$ and Hong Pang ${ }^{1 *}$

\begin{abstract}
Background: Members of the genus Novius Mulsant, 1846 (= Rodolia Mulsant, 1850) (Coleoptera, Coccinellidae), play important roles in the biological control of cotton cushion scale pests, especially those belonging to /cerya. Since the best-known species, the vedalia beetle Novius cardinalis (Mulsant, 1850) was introduced into California from Australia, more than a century of successful use in classical biological control, some species of Novius have begun to exhibit some field adaptations to novel but related prey species. Despite their economic importance, relatively little is known about the underlying genetic adaptations associated with their feeding habits. Knowledge of the genome sequence of Novius is a major step towards further understanding its biology and potential applications in pest control.
\end{abstract}

Results: We report the first high-quality genome sequence for Novius pumilus (Weise, 1892), a representative specialist of Novius. Computational Analysis of gene Family Evolution (CAFE) analysis showed that several orthogroups encoding chemosensors, digestive, and immunity-related enzymes were significantly expanded $(P<0.05)$ in N. pumilus compared to the published genomes of other four ladybirds. Furthermore, some of these orthogroups were under significant positive selection pressure $(P<0.05)$. Notably, transcriptome profiling demonstrated that many genes among the significantly expanded and positively selected orthogroups, as well as genes related to detoxification were differentially expressed, when N. pumilus feeding on the nature prey Icerya compared with the no feeding set. We speculate that these genes are vital in the Icerya adaptation of Novius species.

Conclusions: We report the first Novius genome thus far. In addition, we provide comprehensive transcriptomic resources for $N$. pumilus. The results from this study may be helpful for understanding the association of the evolution of genes related to chemosensing, digestion, detoxification and immunity with the prey adaptation of insect predators. This will provide a reference for future research and utilization of Novius in biological control programs. Moreover, understanding the possible molecular mechanisms of prey adaptation also inform mass rearing of N. pumilus and other Novius, which may benefit pest control.

Keywords: Genome, Transcriptome, Biological control, Ladybird, Novius, Novius pumilus, Prey adaptation

*Correspondence: Isshpang@mail.sysu.edu.cn

${ }^{\dagger}$ Xue-Fei Tang and Yu-Hao Huang contributed equally to this work.

${ }^{1}$ State Key Laboratory of Biocontrol, School of Life Sciences / School

of Ecology, Sun Yat-sen University, Guangzhou, Guangdong, China

Full list of author information is available at the end of the article

\section{Background}

Ladybirds (Coleoptera, Coccinellidae) are a group with diverse feeding habits. Most of them are specialist feeders, while some species have a much wider range of prey [1]. Evolutionary studies have suggested that the ancestors of modern ladybirds switched from mycophagy to scale insects feeding, and some species have 
even shifted the feeding behaviors to plants, mites, whiteflies and aphids [2, 3]. However, Novius Mulsant, 1846 (= Rodolia Mulsant, 1850) (Coleoptera, Coccinellidae) still maintains the characteristics of specifically feeding on scale pests. Beetles in the Novius are probably best known for their extensive use as biological control agents, mainly targeting cotton cushion scale species (Margarodidae), especially those belonging to Icerya (hereafter we use Icerya and cottony cushion scale interchangeably) $[4,5]$. One example is that the introduction of the vedalia beetle, Novius cardinalis (Mulsant, 1850), from Australia to California achieved great success in controlling the cottony cushion scales, Icerya purchasi Maskell, 1879, which was a milestone in contemporary biological control $[6,7]$.

Another famous member in Novius, Novius pumilus (Weise, 1892) (=Rodolia pumila Weise, 1892), has also been widely used in biocontrol for I. aegyptiaca and I. seychellarum in Spain, Peru and the islands of Micronesia, etc. $[8,9]$. N. pumilus is native to the East, and very common in southern China [10]. Similar to N. cardinalis, both adults and larvae of N. pumilus mainly prey on Icerya pests, including I. purchasi Maskell, I. seychellarum (Westwood), and I. aegyptiaca Douglas. Female adults of $N$. pumilus usually lay their eggs in exposed sites in the vicinity of prey; otherwise, they oviposit directly underneath the prey [11]. The newly hatched larvae often penetrate into the oocysts of Icerya and their second- and third-instar nymphs to feed under the abdomen [12]. As a native species, $N$. pumilus is well adapted to the local environment in China, and there is no potential risk of invasion. Therefore, $N$. pumilus exhibits huge advantages in controlling Icerya pests in China. However, the relevant molecular mechanisms underlying the adaptation of $N$. pumilus to the prey Icerya are still unclear.

The adaptations to a very large range of food sources and the acquisition of multiple nutritional niches marks the remarkable evolutionary success of insects [13]. Previous studies have shown that the physiological and biochemical processes of chemosensing, digestion and detoxification could largely affect the feeding range and diet adaptation processes of insects [14-22]. For instant, the gene families that encode odorant-binding proteins and odorant receptors (ORs) act important roles in the lifestyle of insect species, allowing them to locate new sources of diet $[23,24]$. In addition, diet is also found to be able to shape insect immunity $[13,25]$, and insects have developed an immune system to adapt to the changes in diet and microbiota in different environments [26]. Accordingly, a comprehensive investigation to genomic and transcriptomic features would be helpful for exploring the mechanisms that might be involved in prey adaptation of Novius.
In this study, we present a high-quality draft genome of $N$. pumilus. Through comparative and evolutionary analyses with genomes of other four ladybirds, we aimed to investigate the genomic basis underlying the feeding habits of N. pumilus. Moreover, we further examined the differences in transcriptional regulations between feeding and not feeding treatments of larvae and adults of $N$. pumilus, respectively, to explore the mechanism of the feeding habit and adaptation of N. pumilus to Icerya. Our findings would shed light on the utilization of Novius in biocontrol.

\section{Results}

\section{General genomic features of $N$. pumilus}

A total of 48.82 gigabase pairs $(\mathrm{Gb})$ of raw data, where $45.36 \mathrm{~Gb}$ are of high quality (clean reads), were generated with PromethION DNA sequencing (Oxford Nanopore, UK). Furthermore, we sequenced $128 \mathrm{~Gb}$ additional data using Illumina platform. The Nanopore data were first assembled using Wtdbg v 2.2 [27], followed by polishing with Racon v1.32 [28] and Pilon v1.21 [29], which produced a $176.16 \mathrm{Mb}$ genome assembly with 942 contigs with a Contig N50 of $7.58 \mathrm{Mb}$ and L50 of 8 in this study (Table 1). The genome of $N$. pumilus has the smallest Contig L50 and relatively large N50 compared to those of the other 13 Coleoptera genomes.

In total, about $96.39 \%$ reads and $92.05 \%$ paired-end reads were mapped to the assembled genome. The coverage of the Nanopore and Illumina data is $242 \times$ and $640 \times$, respectively. Besides, the application of the Benchmarking Universal Single-Copy Orthologs (BUSCO, Insecta set) pipeline [39] showed that the N. pumilus genome compared well with the other insect genomes in the OrthoDB v10.1 database [40], in terms of completeness. We found approximately 1337 orthologous complete genes (C: 97.8\%; including 1305 orthologous complete genes and single-copy genes (S: 95.5\%) and 32 orthologous complete genes and duplicates (D: $2.3 \%)$ ), 7 orthologous fragmented genes (F: $0.5 \%$ ) and 23 missing genes (M: 1.7\%) (Additional file 1: Table S1), indicating that the genome was of good quality.

\section{Genome annotation}

Annotation of the $N$. pumilus genome was carried out using FunAnnotate v1.8.1 [41], and yielded a final set of 15,772 genes and 17,195 protein sequences. Application of the BUSCO pipeline showed that this gene set had $96.1 \%$ complete genes $(94.1 \%$ single-copy genes and $2 \%$ duplicates), $1.5 \%$ fragmented genes and $2.4 \%$ missing genes at the protein level in the Insecta set of OrthoDB (Fig. 1B; Additional file 1: Table S1). In the functional annotation of this protein set, 14,691 (85.4\%) were found in the National Center for Biotechnology Information 
Table 1 The basic information of the 14 Coleoptera species genomes used in this study

\begin{tabular}{|c|c|c|c|c|c|c|c|c|}
\hline Species & Family & Genome size (Mb) & Contigs & ContigN50 (bp) & Contig L50 & Scaffold N50 (bp) & Scaffold L50 & Reference \\
\hline $\begin{array}{l}\text { Agrilus planipennis } \\
\text { Fairmaire, } 1888\end{array}$ & Buprestidae & 353.06 & 23,186 & 28,329 & 3132 & $1,113,421$ & 91 & [30] \\
\hline $\begin{array}{l}\text { Photinus pyralis (Lin- } \\
\text { naeus, 1767) }\end{array}$ & Lampyridae & 471.51 & 7909 & 170,308 & 757 & $47,017,841$ & 5 & [31] \\
\hline $\begin{array}{l}\text { Nicrophorus } \\
\text { vespilloides Herbst, } \\
1783\end{array}$ & Staphylinidae & 195.27 & 8129 & 67,958 & 623 & 122,407 & 344 & [32] \\
\hline $\begin{array}{l}\text { Onthophagus taurus } \\
\text { (Schreber, 1759) }\end{array}$ & Scarabaeidae & 267.08 & 10,620 & 101,202 & 519 & 337,157 & 160 & [30] \\
\hline $\begin{array}{l}\text { Novius pumilus } \\
\text { (Weise, 1892) }\end{array}$ & Coccinellidae & 176.16 & 942 & $7,579,481$ & 8 & - & - & This study \\
\hline $\begin{array}{l}\text { Cryptolaemus } \\
\text { montrouzieri Mulsant, } \\
1850\end{array}$ & Coccinellidae & 988.11 & 398 & $10,375,940$ & 26 & - & - & [13] \\
\hline $\begin{array}{l}\text { Harmonia axyridis } \\
\text { (Pallas, 1773) }\end{array}$ & Coccinellidae & 423 & 2785 & $1,254,346$ & 79 & $2,054,022$ & 44 & [33] \\
\hline $\begin{array}{l}\text { Coccinella septem- } \\
\text { punctata Linnaeus, } \\
1758\end{array}$ & Coccinellidae & 556.17 & 66,468 & 21,314 & 5248 & 67,752 & 709 & [34] \\
\hline $\begin{array}{l}\text { Propyleajaponica } \\
\text { (Thunberg) }\end{array}$ & Coccinellidae & 803.93 & 4778 & 813,984 & 177 & $100,336,366$ & 4 & [35] \\
\hline $\begin{array}{l}\text { Tribolium castaneum } \\
\text { (Herbst, 1797) }\end{array}$ & Tenebrionidae & 204 & 7059 & 73,049 & 512 & $4,456,720$ & 12 & [36] \\
\hline $\begin{array}{l}\text { Aethina tumida Mur- } \\
\text { ray, } 1867\end{array}$ & Nitidulidae & 234 & 3063 & 298,879 & 193 & - & - & [37] \\
\hline $\begin{array}{l}\text { Dendroctonus } \\
\text { ponderosae (Hopkins, } \\
\text { 1902) }\end{array}$ & Curculionidae & 252.85 & 40,744 & 10,101 & 5474 & 465,763 & 137 & [38] \\
\hline $\begin{array}{l}\text { Anoplophora glabrip- } \\
\text { ennis (Motschulsky, } \\
\text { 1854) }\end{array}$ & Cerambycidae & 706.95 & 26,749 & 80,490 & 2230 & 678,234 & 269 & [19] \\
\hline $\begin{array}{l}\text { Leptinotarsa decem- } \\
\text { lineata Say, } 1824\end{array}$ & Chrysomelidae & 641.99 & 45,556 & 46,596 & 3600 & 139,046 & 1179 & [18] \\
\hline
\end{tabular}

(NCBI) nonredundant (NR) subset, 10,866 (63.2\%) in Swiss-Prot/UniProt, 11,126 (64.7\%) in at least one protein domain in Pfam, 11,269 (65.5\%) in the Gene Ontology (GO) database, and 5071 (29.5\%) in the Kyoto Encyclopedia of Genes and Genomes (KEGG) pathway database [42] (Additional file 1: Table S2).

\section{Gene content comparison}

We identified 21,017 orthogroups (OGs) using OrthoFinder v2.4.0 [43] among $N$. pumilus and the other 13 coleopteran insects included in our analyses (Table 1). Of them, 5818 OGs (7038N. pumilus genes) were present in all coleopteran insects analyzed in this study. A total of 14,283 OGs in N. pumilus clustered with the other beetle species, and 281 OGs were found to be unique to N. pumilus, consisting of 1382 genes (Additional file 2: Table S1). GO enrichment analysis revealed that these unique OGs were enriched in cysteine-type peptidase activity and serine-type endopeptidase activity (false discovery rate $($ FDR $)<0.05)$.

\section{Gene selection and gene family evolution in N. pumilus} To access the genomic basis underlying the N. pumilusspecific adaptation to Icerya, we performed genomewide comparative analyses with other four ladybirds and nine outgroup beetles to identify the gene families under expansion/contraction, as well as the positively selected genes, in the genome of $N$. pumilus.

Firstly, a positive selection analysis based on the singlecopy orthologous genes was performed on the genome of $N$. pumilus by aligning coding sequences (CDSs) from each OG to their orthologs in the 13 other beetles using branch-site model detection in CodeML [44] (Table 1). A total of 711 codon alignments were generated from 971 single-copy genes, while the others were excluded due to codon-to-protein inconsistency, which might have been caused by the different gene predictions in the database. The branch-site model showed that 88 genes were under significant positive selection pressure (likelihood ratio test (LRT), $P<0.05)$ among the 711 single-copy genes (Additional file 2: Table S2). Of them, four encode leucine 


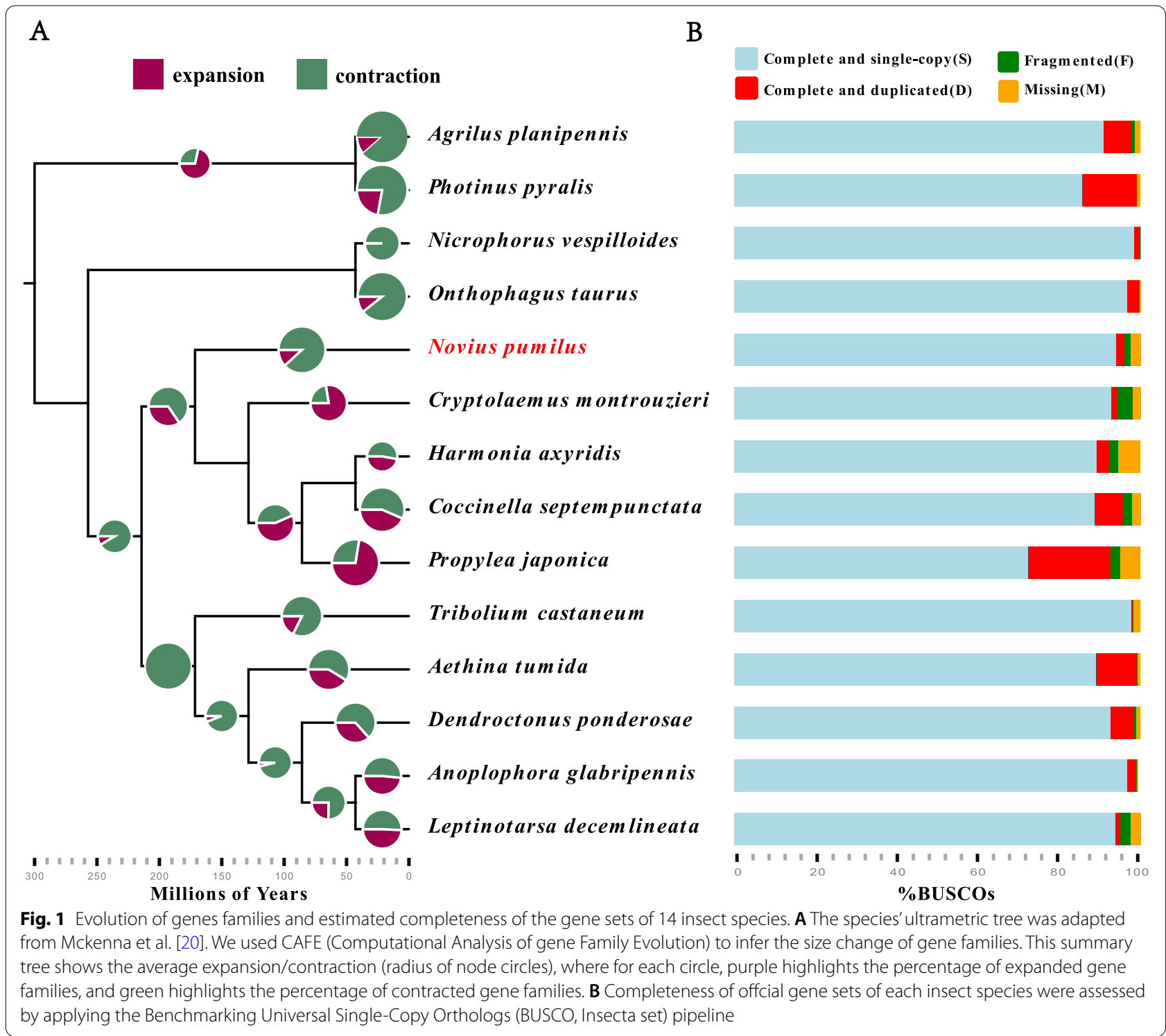

rich repeats (LRRs) related to immunity and one encodes glycosyltransferase related to digestion.

Next, we investigated the expansions and contractions of OGs in the N. pumilus genome. As revealed by the clustering algorithm implemented in CAFE v4.2.1 [45], we found that the number of contracted OGs was far greater than that of expanded OGs in the N. pumilus genome (8221 and 1103, respectively). A total of 17 OGs underwent significant expansion $(P<0.05)$, where one encoded chemosensor (specifically, an OR), two encoded digestive enzymes (both of which were papain family cysteine proteases), and two encoded antimicrobial enzymes (namely, an LRR and a gamma interferon inducible lysosomal thiol reductase (GILT)) (Table 2; details are provided in Additional file 2: Table S1). Of the 14 significantlycontracted OGs, one encodes cysteine-rich secretory protein (CRISP) related to digestion (Table 2).

The GO enrichment results showed that the enriched expanded OGs were associated with olfactory receptor activity, sensory perception of smell related to olfaction and cysteine-type peptidase activity related to digestion (Fig. 2). The significantly enriched contracted OGs were mainly associated with heme binding, DNA integration and intracellular signal transduction (Fig. 2).

Then, we conducted selective pressure analysis for the OGs with significant expansion or contraction in CAFE $(P<0.05)$ to gain a better understanding of the mechanisms of prey adaptation. The results showed that among the 17 OGs with significant expansion and the 14 OGs with significant contraction, 10 and 8 OGs 
Table 2 The number of gene copies that OGs expanded /contracted in N. pumilus than the last common ancestor of ladybirds

\begin{tabular}{|c|c|c|c|c|c|c|c|c|c|}
\hline Annotation & $+I-$ & $P$-value & Pfam & $n^{a}$ & In L Null model & $\begin{array}{l}\text { Alternative } \\
\text { model }\end{array}$ & $\begin{array}{l}\text { Easycodeml } \\
\text { model }\end{array}$ & $2 \Delta \mathrm{l}^{\mathrm{c}}(\mathrm{df}=1)$ & $P$-value \\
\hline $\begin{array}{l}\text { Papain family } \\
\text { cysteine pro- } \\
\text { tease }\end{array}$ & +10 & 0.0293442 & PF00112 & (130) 25 & $-81,374.615334$ & $-81,370.385291$ & $\begin{array}{l}\text { Model A vs. } \\
\text { Model A null }\end{array}$ & 8.460086 & $0.003630247^{*}$ \\
\hline $\begin{array}{l}\text { GIY-YIG catalytic } \\
\text { domain }\end{array}$ & +10 & 0.0115812 & PF01541 & (77) 20 & $-63,449.8$ & $-63,449.8$ & $\begin{array}{l}\text { Model A vs. } \\
\text { Model A null }\end{array}$ & $2.00 \mathrm{E}-06$ & 0.997743 \\
\hline $\begin{array}{l}\text { Zinc finger, } \\
\mathrm{C} 2 \mathrm{H} 2 \text { type }\end{array}$ & +65 & $2.6335 \mathrm{E}-23$ & PF00096 & (78) 71 & $-76,378.4$ & $-76,373.7$ & $\begin{array}{l}\text { Model A vs. } \\
\text { Model A null }\end{array}$ & 9.333846 & $0.002249597^{*}$ \\
\hline $\begin{array}{l}\text { Papain family } \\
\text { cysteine pro- } \\
\text { tease }\end{array}$ & +11 & 0.00067968 & PF00112 & (62) 16 & $-42,889.4$ & $-42,889.1$ & $\begin{array}{l}\text { Model A vs. } \\
\text { Model A null }\end{array}$ & 0.437724 & 0.508223 \\
\hline $\begin{array}{l}\text { Bacterial } \\
\text { extracellular } \\
\text { solute-binding } \\
\text { proteins, fam- } \\
\text { ily } 3\end{array}$ & +55 & $6.5167 E-21$ & PF00497 & (60) 59 & $-65,378.7$ & $-65,372.3$ & $\begin{array}{l}\text { Model A vs. } \\
\text { Model A null }\end{array}$ & 12.70093 & $0.000365475^{* *}$ \\
\hline $\begin{array}{l}\text { Histidine } \\
\text { phosphatase } \\
\text { superfamily } \\
\text { (branch 2) }\end{array}$ & +9 & 0.00432895 & PF00328 & (59) 15 & $-50,522.7$ & $-50,522.7$ & $\begin{array}{l}\text { Model A vs. } \\
\text { Model A null }\end{array}$ & 0 & 1 \\
\hline $\begin{array}{l}\text { Retroviral aspar- } \\
\text { tyl protease }\end{array}$ & +49 & $2.2232 \mathrm{E}-19$ & PF00077 & 52 & $31,763.07136$ & $31,763.07136$ & M1a vs. M2a & 0 & 1 \\
\hline $\begin{array}{l}\text { YqaJ-like viral } \\
\text { recombinase } \\
\text { domain }\end{array}$ & +6 & 0.0286801 & PF09588 & (46) 11 & $-20,486.4$ & $-20,481.5$ & $\begin{array}{l}\text { Model A vs. } \\
\text { Model A null }\end{array}$ & 9.742052 & $0.001800997^{*}$ \\
\hline $\begin{array}{l}\text { CRAL/TRIO } \\
\text { domain }\end{array}$ & +10 & 0.00223833 & PF00650 & (47) 16 & $-32,465.4$ & $-32,462.9$ & $\begin{array}{l}\text { Model A vs. } \\
\text { Model A null }\end{array}$ & 5.072066 & $0.024314388^{*}$ \\
\hline unknown & +43 & $5.7991 \mathrm{E}-17$ & unknown & 46 & $-39,594.10792$ & $-39,394.06476$ & M1a vs. M2a & 400.0863 & $0^{* *}$ \\
\hline $\begin{array}{l}7 \mathrm{tm} \text { Odorant } \\
\text { receptor }\end{array}$ & +14 & 3.346E-05 & PF02949 & (39) 18 & $-28,871.9$ & $-28,867.7$ & $\begin{array}{l}\text { Model A vs. } \\
\text { Model A null }\end{array}$ & 8.308994 & $0.003944924^{*}$ \\
\hline $\begin{array}{l}\text { Leucine rich } \\
\text { repeat }\end{array}$ & +36 & 4.71E-15 & PF13855 & 38 & $31,494.14597$ & $31,494.14597$ & M1a vs. M2a & 0 & 1 \\
\hline unknown & +34 & $3.0939 \mathrm{E}-14$ & unknown & 36 & -3339.182609 & -3330.176841 & M1a vs. M2a & 18.01154 & $0.0001227^{*}$ \\
\hline $\begin{array}{l}\text { Integrase core } \\
\text { domain }\end{array}$ & +6 & 0.0286801 & PF00665 & (35) 11 & $-22,990.3$ & $-22,990.3$ & $\begin{array}{l}\text { Model A vs. } \\
\text { Model A null }\end{array}$ & 0 & 1 \\
\hline unknown & +22 & 2.2991E-09 & unknown & (25) 24 & -8370.951276 & -8369.324548 & $\begin{array}{l}\text { Model A vs. } \\
\text { Model A null }\end{array}$ & 3.253456 & 0.071273 \\
\hline $\begin{array}{l}\text { Domain of } \\
\text { unknown func- } \\
\text { tion (DUF4769) }\end{array}$ & +3 & 0.0234649 & PF15992 & (23) 4 & $-11,711$ & $-11,707.8$ & $\begin{array}{l}\text { Model A vs. } \\
\text { Model A null }\end{array}$ & 6.345562 & $0.011767532^{*}$ \\
\hline $\begin{array}{l}\text { Gamma inter- } \\
\text { feron inducible } \\
\text { lysosomal thiol } \\
\text { reductase (GILT) }\end{array}$ & +18 & $1.1647 \mathrm{E}-08$ & PF03227 & 19 & -8954.59711 & -8930.826609 & M1a vs. M2a & 47.541 & $0^{* *}$ \\
\hline $\begin{array}{l}\text { Core histone } \\
\mathrm{H} 2 \mathrm{~A} / \mathrm{H} 2 \mathrm{~B} / \mathrm{H} 3 / \mathrm{H} 4\end{array}$ & -5 & 0.0475987 & PF00125 & (89) 1 & -8236.68 & -8196.31 & $\begin{array}{l}\text { Model A vs. } \\
\text { Model A null }\end{array}$ & -80.7418 & $0^{* *}$ \\
\hline $\begin{array}{l}\text { Baculovirus FP } \\
\text { protein }\end{array}$ & -6 & 0.00719925 & PF03258 & (87) 0 & $-44,251.4$ & $-44,246.9$ & $\begin{array}{l}\text { Model A vs. } \\
\text { Model A null }\end{array}$ & -8.99553 & $0.002706408^{*}$ \\
\hline Matrixin & -4 & 0.047769 & PF00413 & (80) 0 & $-34,306.30303$ & $-34,295.78115$ & $\begin{array}{l}\text { Model A vs. } \\
\text { Model A null }\end{array}$ & 21.04375 & $0.000004489^{*}$ \\
\hline $\begin{array}{l}\text { Core histone } \\
\mathrm{H} 2 \mathrm{~A} / \mathrm{H} 2 \mathrm{~B} / \mathrm{H} 3 / \mathrm{H} 4\end{array}$ & -5 & 0.0475987 & PF00125 & (77) 1 & -9959.15 & -9959.15 & $\begin{array}{l}\text { Model A vs. } \\
\text { Model A null }\end{array}$ & 2.00E-06 & 0.998872 \\
\hline unknown & -5 & 0.0183516 & unknown & (73) 0 & $-27,707.9$ & $-27,682.2$ & $\begin{array}{l}\text { Model A vs. } \\
\text { Model A null }\end{array}$ & 51.30864 & $0^{* *}$ \\
\hline $\begin{array}{l}\text { Core histone } \\
\mathrm{H} 2 \mathrm{~A} / \mathrm{H} 2 \mathrm{~B} / \mathrm{H} 3 / \mathrm{H} 4\end{array}$ & -4 & 0.047769 & PF00125 & (66) 0 & -4648.924631 & -4617.070009 & $\begin{array}{l}\text { Model A vs. } \\
\text { Model A null }\end{array}$ & 63.7092439999997 & $0^{* *}$ \\
\hline $\begin{array}{l}\text { DDE superfamily } \\
\text { endonuclease }\end{array}$ & -4 & 0.047769 & PF13359 & $(58) 0$ & $-17,817.03628$ & $-17,815.55146$ & M1a vs. M2a & 2.96964 & 0.226543 \\
\hline
\end{tabular}


Table 2 (continued)

\begin{tabular}{|c|c|c|c|c|c|c|c|c|c|}
\hline Annotation & $+I-$ & $P$-value & Pfam & $n^{a}$ & In L Null model & $\begin{array}{l}\text { Alternative } \\
\text { model }\end{array}$ & $\begin{array}{l}\text { Easycodeml } \\
\text { model }\end{array}$ & $2 \Delta \mathrm{I}^{\mathrm{c}}(\mathrm{df}=1)$ & $P$-value \\
\hline RNase $\mathrm{H}$ & -4 & 0.047769 & PF00075 & (51) 0 & $-38,944.3$ & $-38,937.9$ & $\begin{array}{l}\text { Model A vs. } \\
\text { Model A null }\end{array}$ & 12.86602 & $0.000334602^{* *}$ \\
\hline $\begin{array}{l}\text { Retrotransposon } \\
\text { gag protein }\end{array}$ & -4 & 0.047769 & PF03732 & (49) 0 & $-16,647$ & $-16,636.2$ & $\begin{array}{l}\text { Model A vs. } \\
\text { Model A null }\end{array}$ & 21.48437 & $0.000003567^{* *}$ \\
\hline unknown & -4 & 0.047769 & unknown & (46) 0 & $-10,117.57741$ & $-10,103.67858$ & M1a vs. M2a & 27.79766 & $0^{* *}$ \\
\hline $\begin{array}{l}\text { Transposase } \\
\text { protein }\end{array}$ & -4 & 0.047769 & PF12017 & (44) 0 & $-28,053$ & $-28,048.2$ & $\begin{array}{l}\text { Model A vs. } \\
\text { Model A null }\end{array}$ & 9.461622 & $0.002098155^{*}$ \\
\hline $\begin{array}{l}\text { Cysteine-rich } \\
\text { secretory pro- } \\
\text { tein family }\end{array}$ & -4 & 0.047769 & PF00188 & (34) 0 & $-50,366.08197$ & $-50,366.08197$ & $\begin{array}{l}\text { Model A vs. } \\
\text { Model A null }\end{array}$ & 0 & 1 \\
\hline
\end{tabular}

${ }^{\mathrm{a}}$ Number of sequences in the data set

** Signifcant at the $0.1 \%$ level

* Signifcant at the $5 \%$ level

were subjected to significant positive selection $(P<0.05)$, respectively (Table 2 ), as determined by the command Branch Site Model or Site Model in EasyCodeML [46].

\section{Identification and functional analysis of differentially expressed genes}

To clarify the genes that play important roles when $N$. pumilus feeding the cottony cushion scale and investigate the mechanisms underlying its feeding and adaptation to natural preys Icerya, we performed comparative transcriptome analysis between $N$. pumilus individuals feeding or not feeding on I. aegyptiaca. A fold change $>2$ or $<0.5$ and FDR Q-value $<0.05$ were used as the criteria for defining differentially expressed genes (DEGs) in adults and larvae between feeding and not feeding on $I$. aegyptiaca. In total, 1322 DEGs were identified, including 831 downregulated genes and 491 upregulated genes, in the larvae feeding on I. aegyptiaca compared to those without feeding. For convenience, DEGs were labeled "upregulated" or "downregulated" if they were higher or lower expressed when feeding on I. aegyptiaca than not feeding. The fold changes ( $\log 2$ ratios) in the DEGs ranged from -27.82 to 10.56 (Additional file 3: Table S1). We also detected the DEGs in N. pumilus adults between feeding and not feeding on I. aegyptiaca. Compared with the larvae, there were fewer DEGs (91) in the adults, where 40 were upregulated, and 51 were downregulated. The fold changes (log2 ratios) of the DEGs ranged from -7.73 to 23.61 (Additional file 3: Table S2).

Then, we performed Pfam enrichment analyses on the DEGs between the two conditions (feeding vs not feeding) in the larvae and adults, respectively. Sixteen Pfam domain terms were identified to be significantly enriched for the upregulated genes in the larvae $(\mathrm{Q}$-value $<0.05)$, which were mainly related to development, energy metabolism, chemosensing, digestion, detoxification and immunity (Fig. 3). These enriched domain terms included papain family cysteine proteases, cathepsin propeptide inhibitor domain (I29), chitin binding peritrophin-A domain, UDP-glycosyltransferase (UGT), trypsin, GILT, carboxylesterase (COE), LRR proteins, and insect pheromone-binding family (insect PBP). For the adults, the upregulated genes were mainly enriched in LRR, while transcription factors were overrepresented for downregulated genes (Fig. S1 and S2).

In the significantly expanded OGs, genes were found to be overexpressed in the larvae when feeding on I. aegyptiaca. Among them, 11 of 38 LRR and four of 19 GILT genes were significantly upregulated, with some of the log2-fold change values greater than four (i.e., the genes were 16 times more abundant than that they were not feeding; Additional file 3: Table S2). Nine of 16 and six of 25 genes in the two digestion-related homologous gene families of papain cysteine proteases were also significantly upregulated, and some of the log2-fold change values were greater than nine (i.e., the genes were 512 times more abundant than those not feeding on I. aegyptiaca; Additional file 3: Table S2). Comparatively, the adults had fewer significant DEGs in these significantly expanded OGs when feeding on I. aegyptiaca, where only one LRR gene was upregulated and one GILT gene was downregulated.

In both larvae and adults, we also examined the expression levels of all genes from the gene families of digestion, detoxification, chemosensing and immunity, according to Pfam annotations, between feeding and not feeding on I. aegyptiaca. In the larvae, we identified 94 DEGs associated with digestion-related genes when feeding on $I$. aegyptiaca, where 32 DEGs encode trypsin, 27 encode cathepsin propeptide inhibitor I 29 proteins, 33 encode 


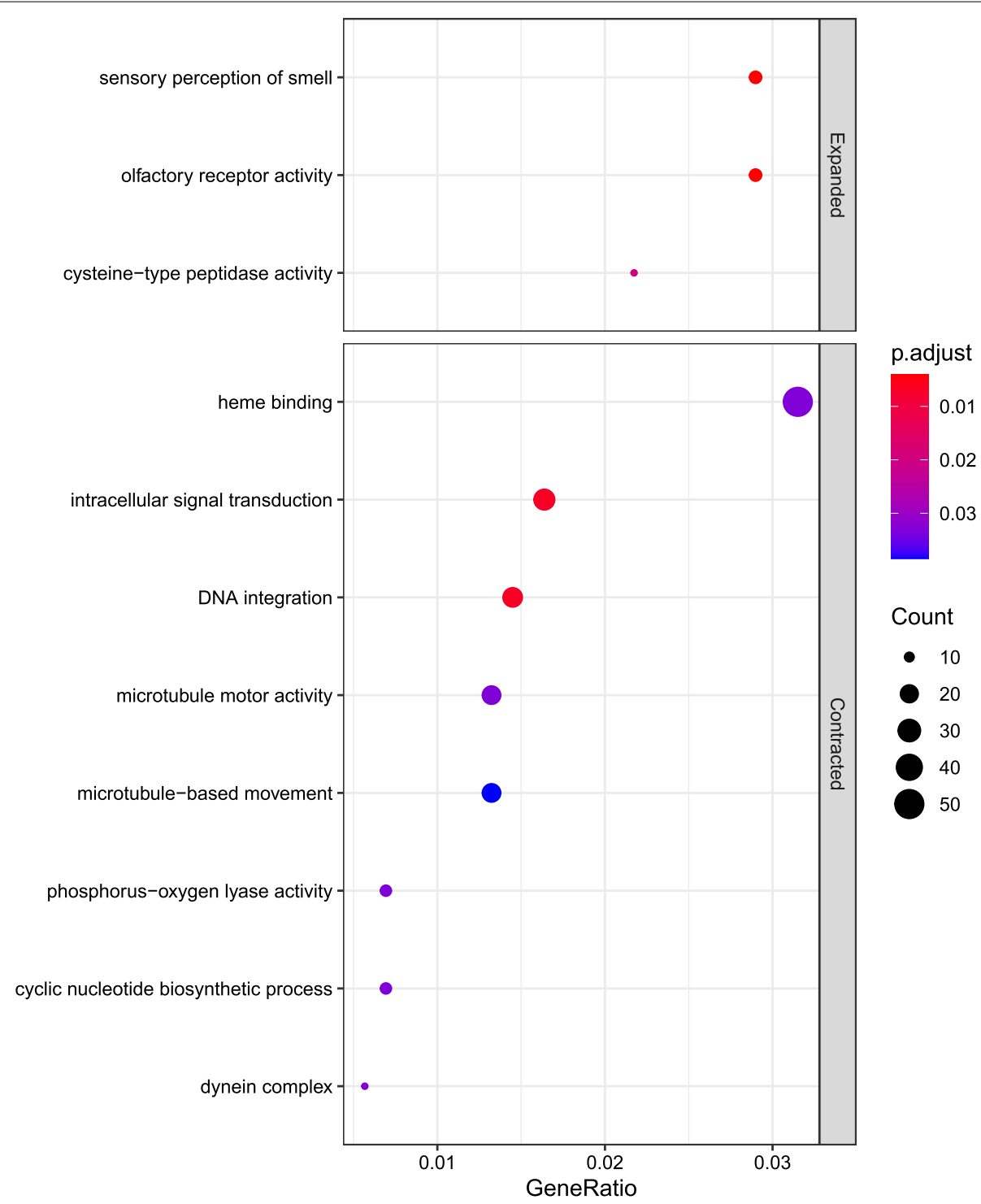

Fig. 2 The GO enrichment of the expanded and contracted families of N. pumilus genome compared to other 13 beetles. The x axis 'GeneRatio' represents the ratio of the DEGs falling in a certain term to the total number of genes annotated in the same term. The $y$ axis is the significant GO terms identified in our analysis. The significance level (adjusted $p$-value) is quantified by the color of circle where more red represents more significance (smaller adjusted $p$-value), while more blue represents less significance (larger adjusted $p$-value)

papain family cysteine proteases, one encodes a GH family protein 18 and one encodes an alpha-amylase. Most of these genes, for example, 32/33 of the papain family cysteine protease and 16/32 of the trypsin genes were upregulated (Fig. 4A).
For the detoxification gene family, genes encoding P450s, UGTs, COEs, ATP-binding cassette (ABC) transporters, and glutathione S-transferases (GSTs) were differentially expressed (Fig. 4B) in the larvae feeding on $I$. aegyptiaca. Among these genes, seven P450, nine UGT,

\section{(See figure on next page.)}

Fig. 3 Function of the studied genes, their accession in Pfam database and result of enrichment analysis of their upregulated DEGs of $N$. pumilus larvae in feeding on I. aegyptiaca and not feeding. Terms with adjusted $p$-value $<0.05$ were considered as significantly enriched. The $x$ axis 'GeneRatio' represents the ratio of the DEGs falling in a certain term to the total number of genes annotated in the same term. The $y$ axis is the significant Pfam terms identified in our analysis. The significance level (adjusted $p$-value) is quantified by the color of circle where more red represents more significance (smaller adjusted $p$-value), while more blue represents less significance (larger adjusted $p$-value) 


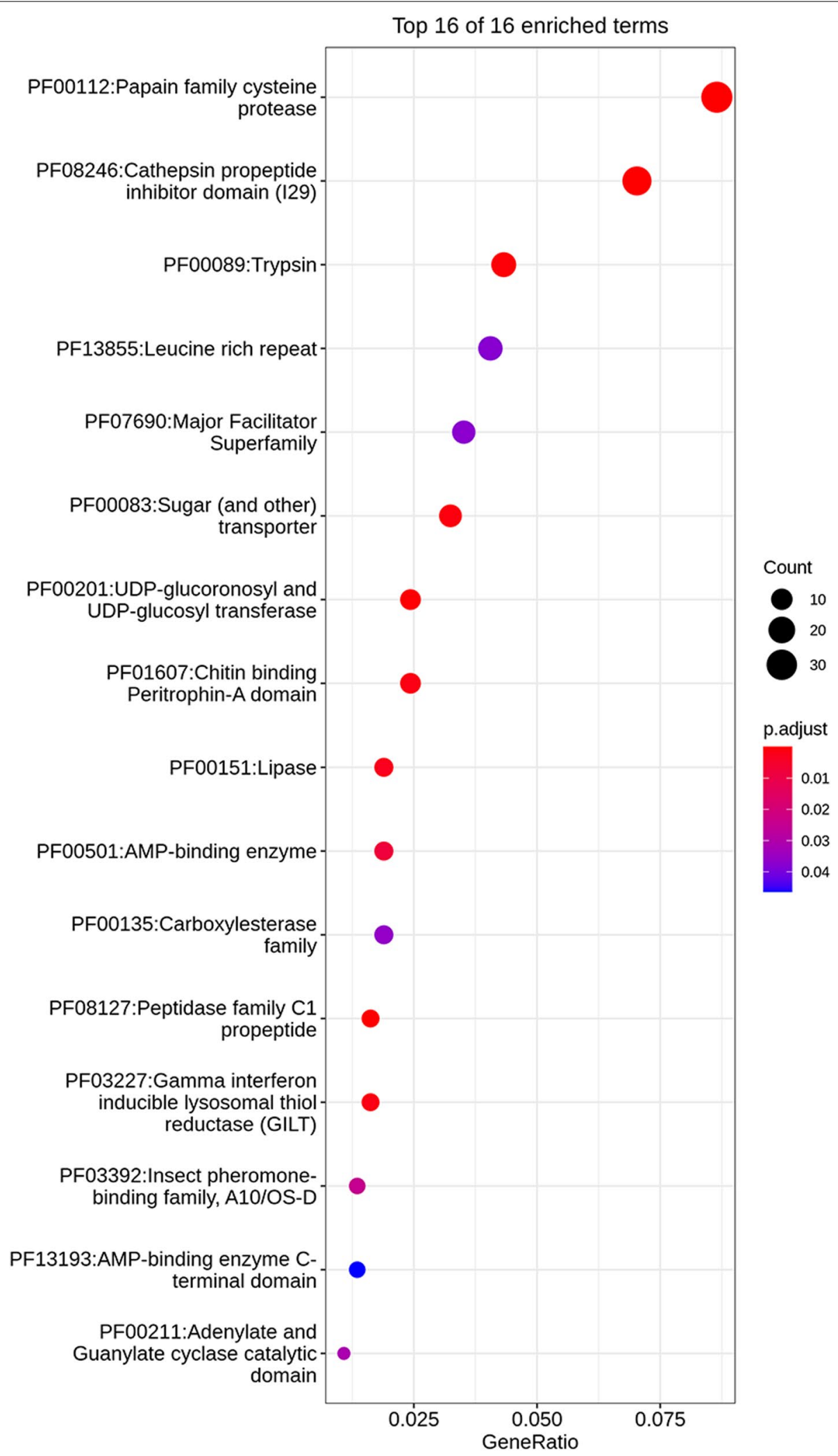

Fig. 3 (See legend on previous page.) 


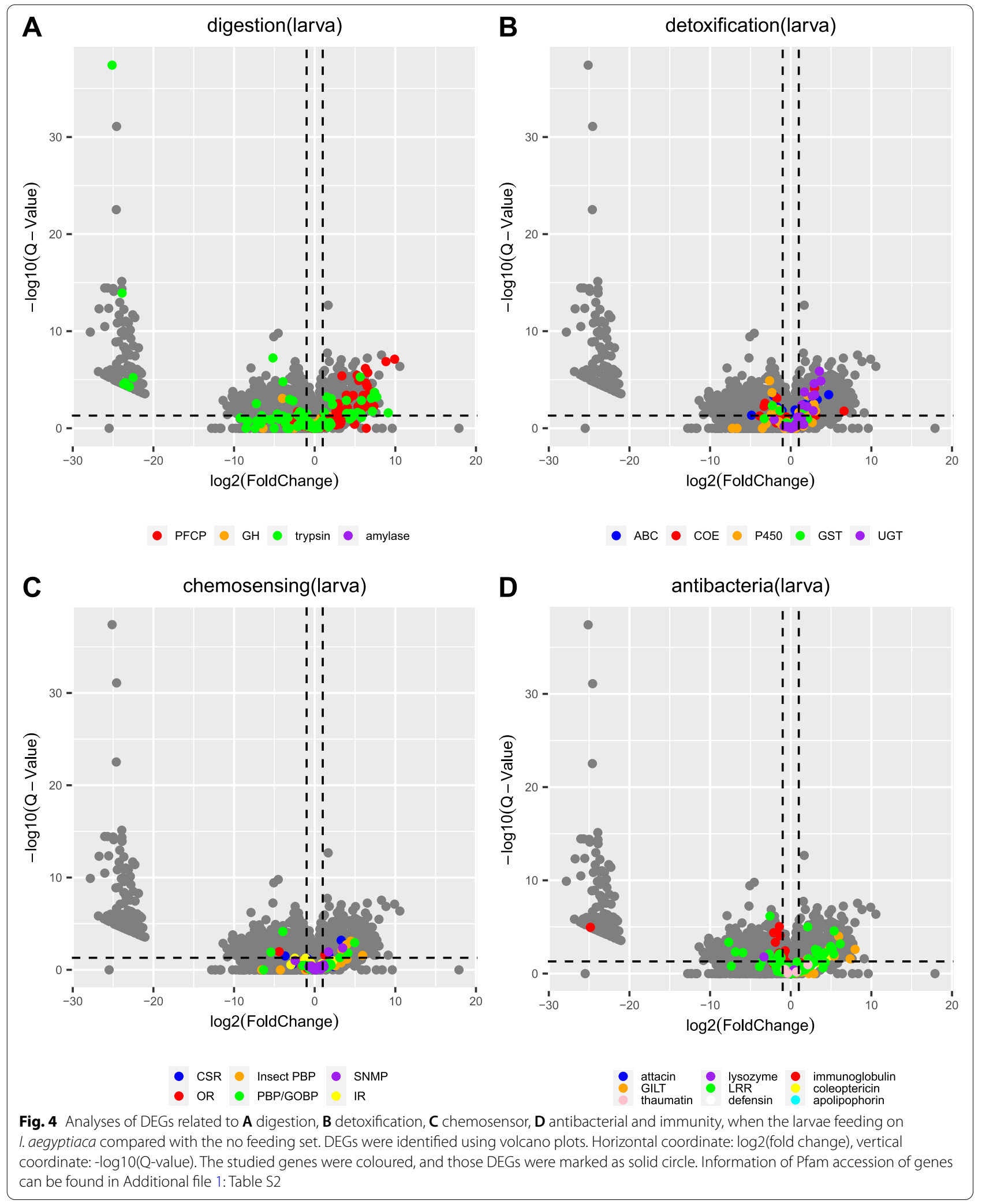


seven $\mathrm{COE}$, five $\mathrm{ABC}$ transporter and one GST genes were upregulated (Fig. 4B). Additionally, we identified five genes encoding OBPs/GOBPs, five encoding chemosensory proteins (CSPs), three encoding chemosensory receptors and two encoding ORs that were significantly differentially expressed in the larvae feeding on I. aegyptiaca (Fig. 4C). Among these chemosensory DEGs, most were upregulated. And all of the CSP and SNMP genes were upregulated. In terms of antibacterial activity or immunity, we found that one gene encoding lysozyme, one gene encoding coleoptericin, six genes encoding GILTs, 16 genes encoding immunoglobulin and 26 genes encoding LRR proteins were differentially expressed when the larvae feeding on I. aegyptiaca compared with not feeding (Fig. 4D). It is worth noting that among the DEGs, all GILT and coleoptericin genes were upregulated, while all immunoglobulin and lysozyme genes were downregulated, during the larvae feeding on I. aegyptiaca (Fig. 4D).

For the N. pumilus adults feeding on I. aegyptiaca, two genes related to digestion were differentially expressed (Fig. 5A), including one downregulated and one upregulated gene both from GH family 1 (Fig. 5A). Three detoxification-related DEGs were identified, including one downregulated $\mathrm{P} 450$ gene, and two upregulated genes encoding COE and one UGT, respectively (Fig. 5B). There were no DEGs among the chemosensory-related genes (Fig. 5C). Among the immunity-related DEGs, six LRR genes were differentially expressed, where five were upregulated (Fig. 5C). In addition, one GILT gene and one thaumatin gene were also upregulated (Fig. 5D).

\section{Discussion}

In the past 20 years, more than 100 insect genomes have been sequenced [47], which largely expand our understanding of the biodiversity of insect habits, behaviors, and long-term evolutionary relationships [48]. However, there are still many species that play important roles in agriculture deserving further study. In this study, we report the first draft genome of N. pumilus, which is of good continuity and high completeness (Additional file 1: Table S1). The size of $N$. pumilus genome was smaller than the 13 other Coleoptera genomes included in our study (Table 1). Comparative evolutionary analysis showed that several OGs related to chemosensor, digestion, and immunity had undergone significant expansion in the N. pumilus genome, and some genes of these OGs were also favored by positive selection (Table 2). With the help of our new completely sequenced $N$. pumilus genome, gene regulation induced by feeding on I. aegyptiaca was explored. Compared to not feeding, DEGs when feeding on the natural prey $I$. aegyptiaca were mainly enriched for development, energy metabolism, chemosensing, digestion/detoxification and immunity, which were similar to the results of OGs expansion and positive selection analyses. These genes are usually involved in the dietary adaptation of both phytophagous and predatory beetles [13], indicating that they may also play important roles in the prey adaptation of N. pumilus.

Insects are always harassed by a wide array of microbial challenges, e.g., pathogenic bacteria, from diets, hence, insects have evolved a strong immune system to cope with the infections $[26,49,50]$. The LRR serves as an important protein binding target in innate [51], and GILT mediates the degradation of endocytosed proteins and alters the immune response characters [52]. In N. pumilus, we found that LRR and GILT gene families were significantly expanded, and the genes from GILT family was also favored by positive selection. At the same time, LRR and GILT genes were found to be significantly upregulated in both adults and larvae feeding on I. aegyptiaca. The enhanced immune process may be due to the adverse impacts induced by the microbial on the surface or in the gut of Icerya, which is the so-called "bacterial challenges". Similarly, in the insect Monochamus saltuarius, these two antimicrobial proteins were reported to play important roles in responding to bacterial challenges [17]. Thus, the above results indicate that LRR and GILT may play crucial roles in promoting the adaptation of $N$. pumilus to the preys. In contrast, $C$. montrouzieri employs different pathways to cope with the nature prey mealybugs, for example, via enhancing immune effector genes [13]. These differences between N. pumilus and C. montrouzieri may reflect the species specificity in immune response mechanisms to the prey of ladybirds.

It is interesting to mention that genes related to digestion and detoxification, which could help to cope with toxic challenges from preys [53-60], were significantly upregulated in the larvae of $N$. pumilus when feeding on I. aegyptiaca compared with not feeding, while there were only few significant DEGs in adults. They, as well as chemosensory genes, likely influence insect behaviors such as searching for food, preference for food, oviposition sites, and mates [61-63]. These differences suggest that though both the adults and larvae of N. pumilus obligately feed on Icerya, they might employ different mechanisms for handling the stress from the prey. Further studies such as electrophysiological and chemical experiments are required to confirm this hypothesis.

Massive expansion of natural enemy insects can guarantee efficient biological control of pests. The availability of a cost-effective natural prey or artificial diet is the key to the successful large-scale production of natural arthropod enemies for biological control [64]. Novius species are highly oligophagous and have important application value in biological control. At present, 


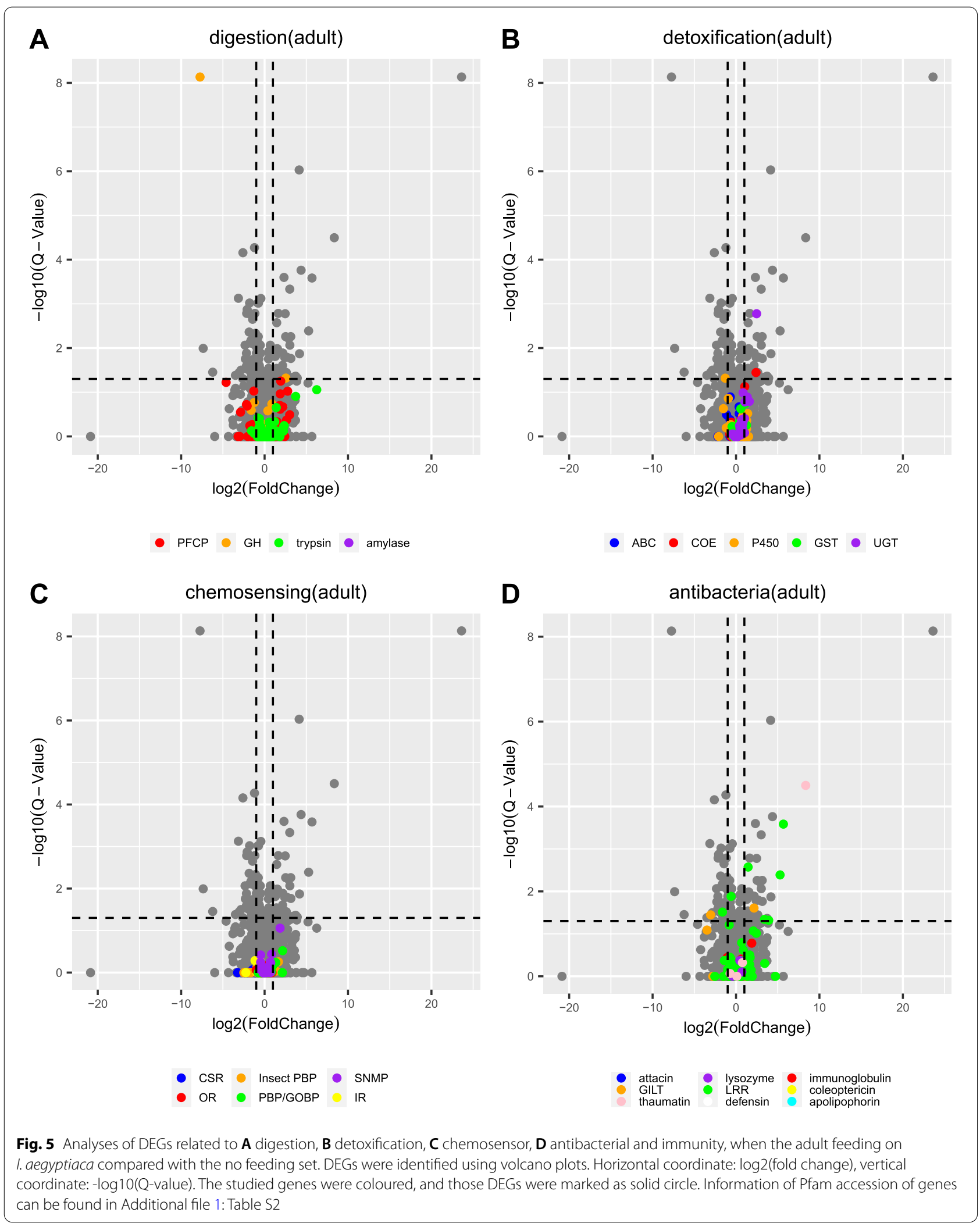


large-scale reproduction of ladybirds in this genus still requires large-scale breeding of their natural prey, which is costly and time consuming. In this study, with the help of our new completely sequenced $N$. pumilus genome, we explored the expanded or contracted OGs and the gene regulations potentially associated with the feeding habits and adaptation to the natural prey Icerya, which provides novel insights into the underlying mechanisms of diet development, as well as speciation.

\section{Conclusions}

The high-quality whole genome sequence of $N$. pumilus reported here provide more insights into the evolutionary interactions between Novius and their preys Icerya. The OGs involved in feeding habits and adaptions, such as chemosensing, digestion and immunity, were significantly expanded, and some genes in the OGs were favored by positive selection. Consistently, these functions were also enhanced when feeding on the nature prey $I$. aegyptiaca. In addition, the processes of chemosensing, digestion and detoxification were more activated in the larvae when feeding than in the adults, suggesting that the mechanism responding to the prey stress may be different between mature and unmature $N$. pumilus individuals. These novel findings enriched the current knowledge on molecular mechanisms of prey adaptation in $N$. pumilus and represent a valuable resource for future application of $N$. pumilus and other Novius species in pest biocontrol. Moreover, deeper studies on prey adaption of Novius species can be operable with the help of our genome.

\section{Methods}

\section{DNA extraction, genome sequencing and assembly}

DNA was extracted from the whole bodies of 21 female adults of $N$. pumilus. These individuals were wild caught from the Magnolia denudata tree in South China Agricultural University, Guangzhou, China. Genomic DNA was extracted using the CTAB method [65]. The quality and concentration of the extracted genomic DNA was measured by $1 \%$ agarose gel electrophoresis and a Qubit fluorimeter (Invitrogen, Carlsbad, CA, USA). High-quality DNA was used for subsequent Nanopore and Illumina sequencing.

Approximately $12 \mu \mathrm{g}$ of genomic DNA was used for preparing Nanopore long-read library. Briefly, genomic DNA was first randomly fragmented, and DNA damage and end were repaired. Sequencing adapters were then ligated to fragmented DNA. The library was sequenced on a PromethION DNA sequencer (Oxford Nanopore, Oxford, UK). The raw data were then filtered to remove short sequence reads $(<5$ kilobase pairs $(\mathrm{kb}))$ and reads with low-quality bases $(\mathrm{Q} 30<90 \%)$ using Nanofilt v2.3.0 [66]. To assemble Nanopore sequencing data, Canu v1.5 [67] was implemented to generate more accurate self-corrected reads with a corrected error rate of 0.05 . Wtdbg v 2.2 [27] was employed for assembly with default settings. Racon v1.32 [28] was performed to correct the assembly with Nanopore reads through two rounds with default settings. And genomic DNA was also sequenced on the Illumina HiSeq X Ten platform (Illumina, San Diego, CA, USA) for further error correction. The Illumina sequenced data were filtered to remove reads with low-quality bases and adapters through Trimmomatic v0.36 [68] with default settings. Pilon v1.21 [29] was applied to correct the Nanopore assembly with Illumina reads through three rounds with default settings.

Primary genome assemblies may contain contamination, such as sequences from symbiotic bacteria, which should be removed. To avoid contamination, we searched the NCBI nucleotide sequence (NT) database (downloaded from https:/ftp.ncbi.nlm.nih.gov/ blast/db) by BLAST v2.8.1+ [69] with a E-value cutoff of $10^{-5}$ and then manually checked the matched hits of the contigs. Forty-two contigs were identified to be from bacteria, which accounts for less $3 \%$ of the total sequences $(4.83 \mathrm{Mb}$ out of $187.59 \mathrm{Mb})$. And these bacteria were mainly intestinal symbiotic bacteria of $N$. pumilus (unpublished results). To ensure the accuracy, these contigs of bacterial origin were filtered out from our downstream analysis.

\section{Genome refinement, gene prediction and functional annotation}

Genome refinement, gene prediction and functional annotation of 5 ladybirds were carried out mainly using FunAnnotate v1.8.1 [41], a gene prediction pipeline, combined with some additional procedures (Additional file 4: Fig. 3). First, the duplicated contigs (27 contigs accounting for $0.33 \mathrm{Mb}$ ) were removed by the "clean" module in the FunAnnotate pipeline, which used Minimap2 [70] to align the shorter contigs to the longer contigs one by one and removed the shorter contigs if the percent identity and the percent coverage of the alignments were both above 95. Contigs with less than 500 bases were also excluded. All contigs were then sorted by length and renamed to prepare downstream gene predictions. The repetitive elements of the prepared genome were identified and masked through the FunAnnotate "mask" module. Repetitive elements were predicted by RepeatModeler v1.0.11 [71], followed by soft masking with RepeatMasker v4.0.9 [72]. The RNA-Seq data of each species in different life stages and under different treatments (Additional file 3: Table S3) were mapped 
using HISAT2 v2.2.0 [73] and were used to generate a genome-guided assembly by Trinity v2.8.5 [74] and StringTie v2.1.4 [75]. Subsequently, PASA v2.4.1 [76] assembly and prediction were performed with Minimap2, GMAP v2019-03-15 [77] and BLAT v36x2 [78] as aligners through the FunAnnotate "train" module, setting the maximum intron length to $20,000 \mathrm{bp}$, because more than $99.5 \%$ of the introns identified in the assembly transcriptome from our previous study are less than 20,000 bp [79]. Gene models were generated by the consensus of various prediction methods through the FunAnnotate "predict" module. The ab initio gene predictions were conducted by SNAP v2006-07-28 [80], AUGUSTUS v3.3.3 [81], GlimmerHMM v3.0.4 [82], GeneMark-ET v4.46 [83] and the ET mode of BRAKER v2.1.1 [84]. HISAT2 RNA-seq alignments were used to train GeneMark-ET and AUGUSTUS, followed by AUGUSTUS optimization. Minimap2, GMAP and BLAT spliced alignments generated in the PASA assembly above were used as transcript evidence. The protein evidence was obtained by Exonerate v2.4.0 [85] alignment after a DIAMOND v2.0.4 [86] search against a customized protein database containing all the proteins in UniProtKB/SwissProt [87] and proteins of the species under Arthropoda in the NR database. Additionally, a high-quality GMAP "gff3_gene" prediction was conducted using complete coding sequence (CDS) from TransDecoder v5.5.0 [88] prediction of the genome-guided transcript assembly obtained above, with identity $>=95 \%$, coverage $=100 \%$ and completely consistent CDS regions. Together with the PASA/TransDecoder prediction, all these predictions were submitted to EVidenceModeler (EVM) v1.1.1 [89] to obtain the final gene models. Repeats were used in EVM consensus model building, the maximum intron length was set as 20,000, and the long introns with more than $500 \mathrm{bp}$ were searched again to find the nested genes. The predictions and their weights used in EVM are listed in Additional file 3: Table S4. PASA was used to capture untranslated regions (UTRs) and refine gene models through the FunAnnotate "update" module. Only alternative transcripts with more than $10 \%$ expression in Kallisto v0.46.0 [90] pseudoalignments compared with the highest transcripts were retained. The problematic gene models were fixed in the FunAnnotate "fix" module.

Then, the predicted proteins were annotated using the FunAnnotate "annotate" module. Domains within the proteins were searched against the Pfam v33.1 [91] database using HMMER v3.3 [92] and the InterPro v71.0 [93] database using InterProScan v5.32 [94]. EggNog and COG annotations were obtained through Eggnog-mapper v2.0.0 (EggNog v5.0) [95, 96]. By combining the results of InterProScan and Eggnog-mapper, we also obtained GO and KEGG pathway annotations.
DIAMOND was used to search UniProtKB/Swiss-Prot, and then, the names and product names of the proteins were identified by combination of the UniProtKB/SwissProt and Eggnog-mapper results. In addition, BUSCO annotations with the Endopterygota set of OrthoDB v9 [97], CAZy [98] annotations by HMMER and MEROPS [99] annotations by DIAMOND were generated. The secreted signal peptides and the transmembrane structures were predicted by SignalP v5.0 [100] and Phobius v1.01 [101]. In addition to the above FunAnnotate annotations, we predicted the mitochondrial transit peptides by TargetP v2.0 [102]. The cutoff for all the E-values above was 1e-5. We provide the flowchart of the FunAnnotate annotation in Additional file 4: Fig. 3.

\section{Orthology search and gene family evolution}

We selected 14 beetle species with different feeding habits for orthologous analysis. Among these species, four are ladybird species of the Coccinellidae family (Coccinella septempunctata, Propylea japonica, Harmonia axyridis and Cryptolaemus montrouzieri) with available genome sequences, and they exhibit apparently a relatively wider prey range than $N$. pumilus. These four ladybirds can feed on aphids, mealybugs and whiteflies [1], while $N$. pumilus mainly feeds on the pests of the Icerya [103]. There have been several genomes of $H$. axyridis sequenced, among which we only selected a chromosome-level genome from Chen et al. (2021) [33] to use in the analysis. And we selected nine representative outgroup species from different families of Coleoptera, which have clear phylogenetic status according to previous studies. Furthermore, the quality of the genome sequencing of these species are high, which are reliable for the analysis. The gene sets of the 14 Coleoptera genomes predicted from RNA-Seq data were used (Table 1) to identify orthologous genes. Then, we used the longest isoforms of the protein sequences of the 14 species as input for OrthoFinder v2.4.0 [43] to identify orthologous genes with default settings. Protein domains within genes were searched against the Pfam v32 database using InterProScan v5.32 with a cutoff E-value of $10^{-5}$. Information on the protein domains was subsequently assigned to the orthogroups using KinFin [104]. Furthermore, these orthogroups were used as input for CAFE v4.2.1 [45] to assess gene family contraction and expansion dynamics using the birth/death parameter $(\lambda)$. The species tree (Fig. 1A) used in CAFE was adapted from a recently published Coleoptera phylogeny [20]. In each branch, OGs with $p$-values $<0.05$ were considered significant expansions or contractions. Furthermore, we performed GO enrichment analysis for the expanded and contracted orthogroups in N. pumilus, using the R 
package ClusterProfiler [105]. Where the significance level ( $p$-value) is assessed based on hypergeometric distribution, and the FDR in multiple comparison is further controlled using an adjusted $p$-value of Benjamini-Hochberg Procedure with the cutoff of 0.05 .

\section{Tests of positive selection}

We used the branch-site model (parameters: null hypothesis: model $=2$, NSsites $=2$, fix_omega $=1$, omega $=1$; alternative hypothesis: model $=2$, NSsites $=2$, fix omega $=0$, omega $=1$ ) in PAML v4.8a [106] to identify the genes with positively selected sites in the $N$. pumilus genome for single-copy ortholog sequences, using the foreground branches in the species tree (Fig. 1A) and labeling at the $N$. pumilus node. Then, LRTs were performed to detect positive selection on the foreground branch. Only those genes with LRT $p$-values less than 0.05 were inferred as being positively selected.

In addition, EasyCodeML [46] was used to perform positive selection tests for the multiple-copy OGs that were significantly expanded or contracted in $N$. pumilus compared to other ladybird species by CAFE 4.2 [45] $(P<0.05)$. For most of the OGs, we selected the branchsite model with the models used for single-copy ortholog sequences above and labeled them in the $N$. pumilus clades to perform data analysis. For the lineage-specific OG in N. pumilus or OGs that existed in only the other four ladybirds, we used the site models with M8 vs. M7, M8vs. M8a and M2a vs. M1a as alternative and null models.

\section{Transcriptional regulation}

$N$. pumilus preys mainly on Icerya and has not been reported to feed on other preys in the field. To elucidate the mechanisms underlying its feeding habits and adaptation to the natural prey Icerya pests. We selected fourth-instar larvae and female adults feeding on the natural prey $I$. aegyptiaca as the experimental materials and maintained under laboratory conditions (temperature: $25 \pm 1{ }^{\circ} \mathrm{C}$; relative humidity $(\mathrm{RH}): 75 \pm 5 \%$; photoperiod: 14:10 (L:D) h). Adults and larvae of $N$. pumilus were fed on I. aegyptiaca or not fed, respectively, for $24 \mathrm{~h}$. During experiments, each individual was placed in a separate plastic Petri dish $(3.5 \mathrm{~cm}$ diameter and $1.2 \mathrm{~cm}$ height). One individual was used as one biological replicate, and six adult replicates and four larvae replicates of each treatments were sequenced. The total RNA of each individual was extracted using TRIzol reagent (CWBIO, Beijing, China). RNA quality and quantity were determined using a Nanodrop 1000 spectrophotometer (Thermo Fisher Scientific, Wilmington, USA). Only RNA samples with a $260 / 280$ ratio from 1.8 to 2.0 , a $260 / 230$ ratio from 2.0 to 2.5 and an RNA integrity number (RIN) greater than 8.0 were used for sequencing. Sequencing was performed on the Illumina HiSeq 2500 platform, generating $2 \times 125 \mathrm{bp}$ (Base pairs) reads. Adaptors and low-quality sequences were removed using the default settings for Trimmomatic v0.36 [68].

Initially, indexing of the reference genome and alignment of reads to the reference genome was performed using HISAT2 [73]. The aligned reads were then used for transcript quantification using StringTie v2.1.4 [75]. Genes with low expression were filtered to avoid false positives in the differential expression analysis. We used a filter method similar to that provided in the edgeR package [107]. In detail, the rows of counts of genes containing more than 4 samples with counts per million (CPM) greater than 1.0 were retained, and others were filtered. Trimmed Mean of M-values (TMM) normalization of the expression counts was conducted by the edgeR package. Then, the TMM value was used to generate the heatmaps. The coefficient of determination $\left(r^{2}\right)$ from Pearson's correlation analysis was used to analyze the relationship of each sample pair based on TMM values. The regulation of gene expression in each pair of comparations was tested using the Bioconductor package DESeq2 [108], with a fold change $>2$ or $<0.5$ and a false FDR Q-value $<0.05$ used as the criteria for defining DEGs. We used N. pumilus without feeding as a control to test for transcriptional regulation with feeding on the natural prey I. aegyptiaca. We investigated the Pfam domains that the DEGs were involved in and evaluated the statistical significance of the Pfam enrichment results by hypergeometric distribution testing using clusterProfiler package [105]. $P$-values were further adjusted for multiple testing using Benjamini-Hochberg Procedure with the cutoff of 0.05 .

\footnotetext{
Abbreviations

ABC: ATP binding cassette transporter; bp: Base pairs; BUSCO: Benchmarking Universal Single-Copy Orthologs; CAFE: Computational Analysis of gene Family Evolution; COE: Carboxylesterase; CSR: Chemosensory receptor; Gb: Gigabase pairs; GH: Glycosyl hydrolase; GILT: Gamma interferon inducible lysosomal thiol reductase; GO: Gene Ontology; GST: Glutathione S-transferase; Insect PBP: Insect pheromone-binding family, A10/OS-D; IR: Ionotropic receptor; kb: Kilobase pairs; KEGG: Kyoto Encyclopedia of Genes and Genomes; LRR: Leucin erich repeat; LRT: Likelihood ratio test; Mb: MEGABASE pairs; ML: Maximum likelihood; OBP: Odorant binding protein; OR: Odorant receptor; P450: Cytochrome P450; PFCP: papain family cysteine protease; TMM: Trimmed Mean of M-values; SNMP: Sensory neuron membrane protein; UGT: UDP-glucuronosyltransferase.
} 


\section{Supplementary Information}

The online version contains supplementary material available at https://doi. org/10.1186/s12864-022-08299-w.

Additional file 1: Table S1. Completeness of genome/gene set of each insect species in this study were assessed by applying the Benchmarking Universal Single-Copy Orthologs (BUSCO, Insecta set) pipeline and the expansion/contraction of gene copy numbers of orthogroups in 14 species. Table S2. Functional annotation of the gene set predicted from the genome of Novius pumilus.

Additional file 2: Table S1. Information on the orthologous groups identified by OrthoFinder and the $p$-value in the branch of Novius pumilus estimated by CAFE. Table S2. The genes under significant positive selection pressure (likelihood ratio test $(\mathrm{LRT}), P<0.05$ ) by branch-site model among the 711 single-copy genes of Novius pumilus.

Additional file 3: Table S1. Details of transcriptome profiling of Novius pumilus larvae under feeding on the nature prey Icerya aegyptiaca and not feeding. Expression of genes of feeding the Icerya aegyptiaca treatments were compared to those of the not feeding treatment in larvae. Table S2. Details of transcriptome profiling of Novius pumilus adults under feeding on the nature prey Icerya aegyptiaca and not feeding. Expression levels of genes of feeding on the Icerya aegyptiaca treatments were compared to those of the not feeding treatment in adults. Table S3. The RNA-Seq datas we used for genome annotation of each ladybird species. Table S4. The predictions and their weights used in EVM.

Additional file 4: Figure S1. Function of the studied genes, their accession in Pfam database and result of enrichment analysis of their upregulated DEGs of Novius pumilus adults in feeding on Icerya aegyptiaca and not feeding. Terms with $\mathrm{Q}$ value $<0.05$ were considered as significantly enriched. Figure $\mathbf{S 2}$. Function of the studied genes, their accession in Pfam database and result of enrichment analysis of their downregulated DEGs of Novius pumilus adults in feeding on /cerya aegyptiaca and not feeding. Terms with $Q$ value $<0.05$ were considered as significantly enriched. Figure S3. Pipeline of genome annotation of the ladybird genomes using FunAnnotate.

\section{Acknowledgements}

We would like to thank Li-Jun Ma, Bo-Yuan Qiu, Sen-Rui Gong and Pei-Fang Zhang of Sun Yat-sen University for assistance with the experiments.

\section{Authors' contributions}

TXF and PH designed the study. TXF, CPT, YHY, LYS, DXY, LZH and LEF performed the laboratory work. TXF, LHS and $\mathrm{HYH}$ analyzed the data. TXF, HYH, YYC and PH wrote the manuscript. All authors read and approved the final manuscript.

\section{Funding}

This work was supported by the National Natural Science Foundation of China (Grant No. 31970439 to HP), Science and Technology Planning Project of Guangzhou, China (Grant No. 201904020041 to HP and 202102020818 to HSL) and Guangdong Basic and Applied Basic Research Foundation (Grant No. 2021A1515011051 to HSL).

\section{Availability of data and materials}

The raw and assembled sequenced data of $\mathrm{N}$. pumilus were deposited in the NCBI BioProject: PRJNA626074 https://www.ncbi.nlm.nih.gov/bioproject/ PRJNA626074.

The RNA-Seq raw data of N. pumilus were deposited in the Sequence Read Archive (SRA) repository of the NCBI under accession Nos. SRR15420491 SRR15420510 of BioProject PRJNA753304 https://www.ncbi.nlm.nih.gov/biosa mple/?LinkName=bioproject_biosample_all\&from_uid=753304.

\section{Declarations}

Ethics approval and consent to participate Not applicable.

\section{Consent for publication}

Not applicable.

\section{Competing interests}

The authors declare that they have no competing interests.

\section{Author details}

'State Key Laboratory of Biocontrol, School of Life Sciences / School of Ecology, Sun Yat-sen University, Guangzhou, Guangdong, China. ${ }^{2}$ School of Biological Sciences, University of Queensland, Brisbane, Queensland, Australia.

Received: 11 August 2021 Accepted: 10 January 2022

Published online: 31 January 2022

\section{References}

1. Chen ML, Huang YH, Qiu BY, Chen PT, Du XY, Li HS, et al. Changes in life history traits and transcriptional regulation of Coccinellini ladybirds in using alternative prey. BMC Genomics. 2020;21:44.

2. Giorgi JA, Vandenberg NJ, McHugh JV, Forrester JA, Silpinski SA, Miller $\mathrm{KB}$, et al. The evolution of food preferences in Coccinellidae. Biol Control. 2009;51:215-31.

3. Magro A, Lecompte E, Magne F, Hemptinne JL, Crouau-Roy B. Phylogeny of ladybirds (Coleoptera: Coccinellidae): are the subfamilies monophyletic? Mol Phylogenet Evol. 2010;54:833-48.

4. Gordon RD. The Coccinellidae (Coleoptera) of America north of Mexico. NY Entomol Soc. 1985;93:654-78.

5. Causton CE, Lincango MP, Poulsom TG. Feeding range studies of Rodolia cardinalis (Mulsant), a candidate biological control agent of /cerya purchasi Maskell in the Galapagos islands. BioControl. 2004;29:315-25.

6. Caltagirone L, Doutt R. The history of the vedalia beetle importation to California and its impact on the development of biological control. Annu Rev Entomol. 1989;34:1-16.

7. Pang H, Tang XF, Booth RG, Vandenberg N, Forrester J, Mchugh J, et al. Revision of the Australian Coccinellidae (Coleoptera). Genus Novius Mulsant of tribe Noviini. Ann Zool. 2020;70:1-24.

8. Beardsley J. Fluted scales and their biological control in United States administered Micronesia. Proc Hawaiian Entomol Soc. 1955;15:391-9.

9. Schmaedick MA. Background on Seychelles scale in American Samoa and a possible introduction of the lady beetle Rodolia pumila from Tutuila Island to control the scale on Ta'u island: Land Grant Program, American Samoa Community College, American Samoa; 2007.

10. Clausen CP. Introduced parasites and predators of arthropod pests and weeds: a world review. Washington: Agricultural Research Service; 1978.

11. LeSage L. Coccinellidae (Cucujoidea), the lady beetles, ladybirds. In: Stehr FW, eidtor. Immature Insects. Dubuque, lowa, USA: Kendall/Hunt Publishing Co. 1991. p. 485-94.

12. Balduf WV. The bionomics of Entomophagous Coleoptera. New York: Swift; 1935

13. Li HS, Huang YH, Chen ML, Ren Z, Qiu BY, De Clercq P, et al. Genomic insight into diet adaptation in the biological control agent Cryptolaemus montrouzieri. BMC Genomics. 2021;22:35.

14. Pearce SL, Clarke DF, East PD, Elfekih S, Gordon KHJ, Jermiin LS, et al. Genomic innovations, transcriptional plasticity and gene loss underlying the evolution and divergence of two highly polyphagous and invasive Helicoverpa pest species. BMC Biol. 2017;15:63.

15. Cheng T, Wu J, Wu Y, Chilukuri RV, Huang L, Yamamoto K, et al. Genomic adaptation to polyphagy and insecticides in a major East Asian noctuid pest. Nat Ecol Evol. 2017;1:1747-56.

16. Zhong H, Li F, Chen J, Zhang J, Li F. Comparative transcriptome analysis reveals host-associated differentiation in Chilo suppressalis (Lepidoptera: Crambidae). Sci Rep. 2017;7:13778.

17. Hou Z, Wei C. De novo comparative transcriptome analysis of a rare cicada, with identification of candidate genes related to adaptation to a novel host plant and drier habitats. BMC Genomics. 2019:20:182.

18. Schoville SD, Chen YH, Andersson MN, Benoit JB, Bhandari A, Bowsher $\mathrm{JH}$, et al. A model species for agricultural pest genomics: the genome of the Colorado potato beetle, Leptinotarsa decemlineata (Coleoptera: Chrysomelidae). Sci Rep. 2018;8:1931. 
19. McKenna DD, Scully ED, Pauchet Y, Hoover K, Kirsch R, Geib SM, et al. Genome of the Asian longhorned beetle (Anoplophora glabripennis), a globally significant invasive species, reveals key functional and evolutionary innovations at the beetle-plant interface. Genome Biol. 2016;17:227.

20. McKenna DD, Shin S, Ahrens D, Balke M, Beza-Beza C, Clarke DJ, et al. The evolution and genomic basis of beetle diversity. Proc Natl Acad Sci U S A. 2019;116:24729-37.

21. Hazzouri KM, Sudalaimuthuasari N, Kundu B, Nelson D, Al-Deeb MA, Le Mansour A, et al. The genome of pest Rhynchophorus ferrugineus reveals gene families important at the plant-beetle interface. Commun Biol. 2020;3:323.

22. Seppey M, loannidis P, Emerson BC, Pitteloud C, Robinson-Rechavi M, Roux J, et al. Genomic signatures accompanying the dietary shift to phytophagy in polyphagan beetles. Genome Biol. 2019;20:98.

23. Eyun SI, Soh HY, Posavi M, Munro JB, Hughes DST, Murali SC, et al. Evolutionary history of chemosensory-related gene families across the Arthropoda. Mol Biol Evol. 2017;34:1838-62.

24. Krieger J, Raming K, Dewer YME, Bette S, Conzelmann S, Breer H. A divergent gene family encoding candidate olfactory receptors of the moth Heliothis virescens. Eur J Neurosci. 2002;16:619-28.

25. Vogel H, Muller A, Heckel DG, Gutzeit H, Vilcinskas A. Nutritional immunology: diversification and diet-dependent expression of antimicrobial peptides in the black soldier fly Hermetia illucens. Dev Comp Immunol. 2018;78:141-8.

26. Vilcinskas A. Evolutionary plasticity of insect immunity. J Insect Physiol. 2013:59:123-9.

27. Ruan J, Li H. Fast and accurate long-read assembly with wtdbg2. Nat Methods. 2020;17:155-8.

28. Vaser R, Sovic I, Nagarajan N, Sikic M. Fast and accurate de novo genome assembly from long uncorrected reads. Genome Res. 2017;27:737-46

29. Walker BJ, Abeel T, Shea T, Priest M, Abouelliel A, Sakthikumar S, et al. Pilon: an integrated tool for comprehensive microbial variant detection and genome assembly improvement. PLoS One. 2014;9:e112963.

30. Thomas GWC, Dohmen E, Hughes DST, Murali SC, Poelchau M, Glastad $\mathrm{K}$, et al. Gene content evolution in the arthropods. Genome Biol. 2020;21:15.

31. Fallon TR, Lower SE, Chang CH, Bessho-Uehara M, Martin GJ, Bewick AJ, et al. Firefly genomes illuminate parallel origins of bioluminescence in beetles. Elife. 2018;7:e36495.

32. Cunningham CB, Ji LX, Wiberg RAW, Shelton J, McKinney EC, Parker DJ, et al. The genome and methylome of a beetle with complex social behavior, Nicrophorus vespilloides (Coleoptera: Silphidae). Genome Biol Evol. 2015;7:3383-96.

33. Chen MY, Mei Y, Chen X, Chen X, Xiao D, He K, et al. A chromosomelevel assembly of the harlequin ladybird Harmonia axyridis as a genomic resource to study beetle and invasion biology. Mol Ecol Resour. 2021;21:1318-32.

34. Ando T, Matsuda T, Goto K, Hara K, Ito A, Hirata J, et al. Repeated inversions within a pannier intron drive diversification of intraspecific colour patterns of ladybird beetles. Nat Commun. 2018;9:3843.

35. Zhang L, Li S, Luo J, Du P, Wu L, Li Y, et al. Chromosome-level genome assembly of the predator Propylea japonica to understand its tolerance to insecticides and high temperatures. Mol Ecol Resour. 2020;20:292-307.

36. Richards S, Gibbs RA, Weinstock GM, Brown SJ, Denell R, et al. The genome of the model beetle and pest Tribolium castaneum. Nature. 2008;452:949-55.

37. Evans JD, McKenna D, Scully E, Cook SC, Dainat B, Egekwu N, et al. Genome of the small hive beetle (Aethina tumida, Coleoptera: Nitidulidae), a worldwide parasite of social bee colonies, provides insights into detoxification and herbivory. Gigascience. 2018;7:1-16.

38. Keeling CI, Yuen MM, Liao NY, Docking TR, Chan SK, Taylor GA, et al. Draft genome of the mountain pine beetle, Dendroctonus ponderosae Hopkins, a major forest pest. Genome Biol. 2013;14:R27.

39. Waterhouse RM, Seppey M, Simao FA, Manni M, loannidis P, Klioutchnikov G, et al. BUSCO applications from quality assessments to gene prediction and phylogenomics. Mol Biol Evol. 2018;35:543-8.

40. Kriventseva EV, Kuznetsov D, Tegenfeldt F, Manni M, Dias R, Simão FA, et al. OrthoDB v10: sampling the diversity of animal, plant, fungal, protist, bacterial and viral genomes for evolutionary and functional annotations of orthologs. Nucleic Acids Res. 2019;47:D807-D11.

41. Palmer J, Stajich JJZd. Funannotate: eukaryotic genome annotation pipeline 2017. https://funannotate.readthedocs.io/en/latest/.

42. Kanehisa M, Furumichi M, Sato Y, Ishiguro-Watanabe M, Tanabe M. KEGG: integrating viruses and cellular organisms. Nucleic Acids Res. 2021:49:D545-D51.

43. Emms DM, Kelly S. OrthoFinder: phylogenetic orthology inference for comparative genomics. Genome Biol. 2019;20:238.

44. Kohlhase M. CodeML: an open markup format the content and presentatation of program code. Pittsburgh(PA): Computer Science, Carnegie Mellon University; 2006

45. Han MV, Thomas GW, Lugo-Martinez J, Hahn MW. Estimating gene gain and loss rates in the presence of error in genome assembly and annotation using CAFE 3. Mol Biol Evol. 2013;30:1987-97.

46. Gao FL, Chen CJ, Arab DA, Du ZG, He YH, Ho SYW. EasyCodeML: a visual tool for analysis of selection using CodeML. Ecol Evol. 2019;9:3891-8.

47. Yin C, Shen G, Guo D, Wang S, Ma X, Xiao H, et al. InsectBase: a resource for insect genomes and transcriptomes. Nucleic Acids Res. 2016:44:D801-D7.

48. Shi M, Wang Z, Ye X, Xie H, Li F, Hu X, et al. The genomes of two parasitic wasps that parasitize the diamondback moth. BMC Genomics. 2019;20:893.

49. Hultmark D. Immune reactions in Drosophila and other insects: a model for innate immunity. Trends Genet. 1993;9:178-83.

50. Sagisaka A, Miyanoshita A, Ishibashi J, Yamakawa M. Purification, characterization and gene expression of a glycine and proline-rich antibacterial protein family from larvae of a beetle, Allomyrina dichotoma. Insect Mol Biol. 2001;10:293-302.

51. Zhang H, Li S, Wang F, Xiang J, Li F. Identification and functional study of an LRR domain containing membrane protein in Litopenaeus vannamei. Dev Comp Immunol. 2020;109:103713.

52. West LC, Cresswell P. Expanding roles for GILT in immunity. Curr Opin Immunol. 2013;25(1):103-8.

53. Hoang K, Matzkin LM, Bono JM. Transcriptional variation associated with cactus host plant adaptation in Drosophila mettleri populations. Mol Ecol. 2015;24:5186-99.

54. Ragland GJ, Almskaar K, Vertacnik KL, Gough HM, Feder JL, Hahn DA, et al. Differences in performance and transcriptome-wide gene expression associated with Rhagoletis (Diptera: Tephritidae) larvae feeding in alternate host fruit environments. Mol Ecol. 2015;24:2759-76.

55. Vogel H, Musser RO, Celorio-Mancera M. Transcriptome responses in herbivorous insects towards host plant and toxin feeding. Annu Plant Rev. 2014;47:197-233.

56. Liu J, Shi GP, Zhang WQ, Zhang GR, Xu WH. Cathepsin L function in insect moulting: molecular cloning and functional analysis in cotton bollworm, Helicoverpa armigera. Insect Mol Biol. 2006;15:823-34.

57. Uchida K, Ohmori D, Ueno T, Nishizuka M, Eshita Y, Fukunaga A, et al. Preoviposition activation of cathepsin-like proteinases in degenerating ovarian follicles of the mosquito Culex pipiens pallens. Dev Biol. 2001;237:68-78.

58. Cristofoletti PT, Ribeiro AF, Terra WR. The cathepsin L-like proteinases from the midgut of Tenebrio molitor larvae: sequence, properties, immunocytochemical localization and function. Insect Biochem Mol Biol. 2005;35:883-901.

59. Nisbet AJ, Billingsley PF. A comparative survey of the hydrolytic enzymes of ectoparasitic and free-living mites. Int J Parasitol. 2000;30:19-27.

60. Horn M, Nussbaumerova M, Sanda M, Kovarova Z, Srba J, Franta Z, et al. Hemoglobin digestion in blood-feeding ticks: mapping a multipeptidase pathway by functional proteomics. Chem Biol. 2009;16:1053-63.

61. Wu YM, Liu YY, Chen XS. Genomic content of chemosensory receptors in two sister blister beetles facilitates characterization of chemosensory evolution. BMC Genomics. 2020;21:589.

62. Liu R, He X, Lehane S, Lehane M, Hertz-Fowler C, Berriman M, et al. Expression of chemosensory proteins in the tsetse fly Glossina morsitans morsitans is related to female host-seeking behaviour. Insect Mol Biol. 2012;21:41-8.

63. Fox AN, Pitts RJ, Robertson HM, Carlson JR, Zwiebel LJ. Candidate odorant receptors from the malaria vector mosquito Anopheles gambiae and 
evidence of down-regulation in response to blood feeding. Proc Natl Acad Sci U S A. 2001;98:14693-7.

64. Grenier S. In vitro rearing of entomophagous insects - past and future trends: a minireview. B Insectol. 2009;62:1-6.

65. Milligan BG. Total DNA isolation. In: Hoelzel AR, editor. Molecular genetic analysis of populations. Oxford: Oxford University Press; 1988. p. 29-64.

66. De Coster W, D'Hert S, Schultz DT, Cruts M, Van Broeckhoven C. NanoPack: visualizing and processing long-read sequencing data. Bioinformatics. 2018;34:2666-9.

67. Koren S, Walenz BP, Berlin K, Miller JR, Bergman NH, Phillippy AM. Canu: scalable and accurate long-read assembly via adaptive k-mer weighting and repeat separation. Genome Res. 2017:27:722-36.

68. Bolger AM, Lohse M, Usadel B. Trimmomatic: a flexible trimmer for Illumina sequence data. Bioinformatics. 2014;30:2114-20.

69. Camacho C, Coulouris G, Avagyan V, Ma N, Papadopoulos J, Bealer K, et al. BLAST+: architecture and applications. BMC Bioinformatics. 2009;10:421.

70. Li H. Minimap2: pairwise alignment for nucleotide sequences. Bioinformatics. 2018:34:3094-100

71. Smit A, Hubley R. 2015. RepeatModeler Open-1.0. https://www.repea tmasker.org/RepeatModeler/.

72. Tarailo-Graovac M, Chen N. Using RepeatMasker to identify repetitive elements in genomic sequences. Curr Protoc Bioinformatics. 2009; Chapter 4:Unit 4.10.

73. Kim D, Paggi JM, Park C, Bennett C, Salzberg SL. Graph-based genome alignment and genotyping with HISAT2 and HISAT-genotype. Nat Biotechnol. 2019;37:907-15.

74. Haas BJ, Papanicolaou A, Yassour M, Grabherr M, Blood PD, Bowden J, et al. De novo transcript sequence reconstruction from RNA-seq using the trinity platform for reference generation and analysis. Nat Protoc. 2013;8:1494-512.

75. Pertea M, Pertea GM, Antonescu CM, Chang T-C, Mendell JT, Salzberg SL. StringTie enables improved reconstruction of a transcriptome from RNA-seq reads. Nat Biotechnol. 2015:33:290-5.

76. Haas BJ, Delcher AL, Mount SM, Wortman JR, Smith RK Jr, Hannick LI, et al. Improving the Arabidopsis genome annotation using maximal transcript alignment assemblies. Nucleic Acids Res. 2003:31:5654-66.

77. WU TD, Watanabe CK. GMAP: a genomic mapping and alignment program for mRNA and EST sequences. Bioinformatics. 2005;21:1859-75.

78. Kent WJ. BLAT--the BLAST-like alignment tool. Genome Res. 2002:12:656-64

79. Li HS, Tang XF, Huang YH, Xu ZY, Chen ML, Du XY, et al. Horizontally acquired antibacterial genes associated with adaptive radiation of ladybird beetles. BMC Biol. 2021;19:7.

80. Korf I. Gene finding in novel genomes. BMC Bioinformatics. 2004:5:59

81. Stanke M, Steinkamp R, Waack S, Morgenstern BJNar. AUGUSTUS: a web server for gene finding in eukaryotes. Nucleic Acids Res. 2004:32:W309-W12.

82. Majoros WH, Pertea M, Salzberg SL. TigrScan and GlimmerHMM: two open source ab initio eukaryotic gene-finders. Bioinformatics. 2004;20:2878-9.

83. Lomsadze A, Burns PD, Borodovsky M. Integration of mapped RNA-Seq reads into automatic training of eukaryotic gene finding algorithm. Nucleic Acids Res. 2014:42:e119.

84. Hoff K, Lomsadze A, Borodovsky M, Stanke M. Whole-genome annotation with BRAKER. Methods Mol Biol. 2019;1962:65.

85. Slater GSC, Birney E. Automated generation of heuristics for biological sequence comparison. BMC Bioinformatics. 2005;6:1-11.

86. Buchfink B, Xie C, Huson DH. Fast and sensitive protein alignment using DIAMOND. Nat Methods. 2015;12:59-60.

87. Boutet E, Lieberherr D, Tognolli M, Schneider M, Bansal P, Bridge AJ, et al. UniProtKB/Swiss-Prot, the manually annotated section of the UniProt KnowledgeBase: how to use the entry view. Methods Mol Biol. 2016;1374:23-54.

88. Lechner M, Findeiß S, Steiner L, Marz M, Stadler PF, Prohaska SJ. Proteinortho: detection of (co-) orthologs in large-scale analysis. BMC Bioinform. 2011:12:124.

89. Haas BJ, Salzberg SL, Zhu W, Pertea M, Allen JE, Orvis J, et al. Automated eukaryotic gene structure annotation using EVidenceModeler and the program to assemble spliced alignments. Genome Biol. 2008;9:1-22.
90. Bray NL, Pimentel H, Melsted P, Pachter L. Near-optimal probabilistic RNA-seq quantification. Nat Biotechnol. 2016;34:525-7.

91. El-Gebali S, Mistry J, Bateman A, Eddy SR, Luciani A, Potter SC, et al. The Pfam protein families database in 2019. Nucleic Acids Res. 2019:47:D427-D32.

92. Potter SC, Luciani A, Eddy SR, Park Y, Lopez R, Finn RD. HMMER web server: 2018 update. Nucleic Acids Res. 2018:46:W200-W4.

93. Mitchell AL, Attwood TK, Babbitt PC, Blum M, Bork P, Bridge A, et al. InterPro in 2019: improving coverage, classification and access to protein sequence annotations. Nucleic Acids Res. 2019;47:D351-D60.

94. Quevillon E, Silventoinen V, Pillai S, Harte N, Mulder N, Apweiler R, et al. InterProScan: protein domains identifier. Nucleic Acids Res, 2005;33:W116-W20

95. Cantalapiedra CP, Hernandez-Plaza A, Letunic I, Bork P, Huerta-Cepas J. eggNOG-mapper v2: functional annotation, Orthology assignments, and domain prediction at the metagenomic scale. Mol Biol Evol. 2021;38:5825-9.

96. Huerta-Cepas J, Szklarczyk D, Heller D, Hernandez-Plaza A, Forslund SK, Cook H, et al. eggNOG 5.0: a hierarchical, functionally and phylogenetically annotated orthology resource based on 5090 organisms and 2502 viruses. Nucleic Acids Res. 2019;47:D309-D14.

97. Zdobnov EM, Tegenfeldt F, Kuznetsov D, Waterhouse RM, Simao FA, loannidis P, et al. OrthoDB v9.1: cataloging evolutionary and functional annotations for animal, fungal, plant, archaeal, bacterial and viral orthologs. Nucleic Acids Res. 2017;45:D744-D9.

98. Lombard V, Golaconda Ramulu H, Drula E, Coutinho PM, Henrissat B. The carbohydrate-active enzymes database (CAZy) in 2013. Nucleic Acids Res. 2014;42:D490-D5.

99. Rawlings ND, Barrett AJ, Bateman A. MEROPS: the peptidase database. Nucleic Acids Res. 2010;38:D227-D33.

100. Emanuelsson O, Brunak S, Von Heijne G, Nielsen H. Locating proteins in the cell using TargetP, SignalP and related tools. Nat Protoc. 2007;2:953-71.

101. Käll L, Krogh A, Sonnhammer EL. Advantages of combined transmembrane topology and signal peptide prediction - the Phobius web server. Nucleic Acids Res. 2007;35:W429-W32.

102. Armenteros JJA, Salvatore M, Emanuelsson O, Winther O, Von Heijne $\mathrm{G}$, Elofsson $\mathrm{A}$, et al. Detecting sequence signals in targeting peptides using deep learning. Life Sci Alliance. 2019;2:e201900429.

103. Huang BK, Zhang KC, Huang QQ, et al. Evaluation on the biology and utilization of the Rodolia pumila. In: Huang BK, editor. Proceedings of the National Symposium on Ladybirds. Shanghai: Shanghai Science and Technology Press; 1991. p. 29-33.

104. Laetsch DR, Blaxter ML. KinFin: Software for taxon-aware analysis of clustered protein sequences. G3 (Bethesda). 2017;7:3349-57.

105. Yu GC, Wang LG, Han YY, He QY. clusterProfiler: an R package for comparing biological themes among eene clusters. OMICS. 2012;16:284-7.

106. Yang Z. PAML 4: phylogenetic analysis by maximum likelihood. Mol Biol Evol. 2007:24:1586-91.

107. Robinson MD, McCarthy DJ, Smyth GK. edgeR: a bioconductor package for differential expression analysis of digital gene expression data. Bioinformatics. 2010;26:139-40.

108. Love MI, Huber W, Anders S. Moderated estimation of fold change and dispersion for RNA-seq data with DESeq2. Genome Biol. 2014;15:550.

\section{Publisher's Note}

Springer Nature remains neutral with regard to jurisdictional claims in published maps and institutional affiliations. 